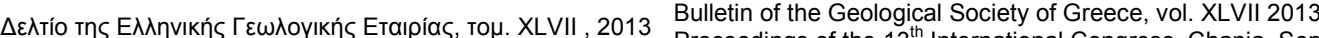
Proceedings of the $13^{\text {th }}$ International Congress, Chania, Sept.

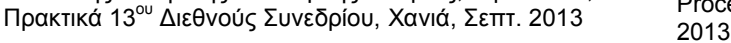

\title{
A MINERALOGICAL STUDY OF PIGMENTS USED IN TWO IAKOVIDIS PAINTINGS: VERIFICATION OF ARTWORK AUTHENTICITY USING RAMAN MICRO-SPECTROSCOPY METHOD
}

\author{
Kougemitrou I. ${ }^{1}$, Economou G. ${ }^{2}$, Giovanopoulos $\mathrm{J}^{3}$, Baziotis I. ${ }^{4,5}$, \\ Leontakianakos G. ${ }^{6}$ and Stathopoulos V.
}

${ }^{1}$ Harokopio University, Department of Geography, 70 El. Venizelou, 17671 Kallithea, Athens, Greece, ekougemitrou@hua.gr

${ }^{2}$ Institute of Geology and Mineral Exploration (IGME), Department of Mineralogy and Petrography, c. entrance, Olympic village, 13677 Acharnai, Greece, dop@igme.gr

${ }^{3}$ Nikias Research Centre of Certification, Maintenance and Restoration of art works, Cyprou 57, Athens, Greece,info@nikias.gr

${ }^{4}$ Department of Mineralogy, Petrology and Economic Geology, School of Geology, Aristotle University of Thessaloniki, 54124,Thessaloniki,Greece,ibaziotis@geo.auth.gr, baziotis@metal.ntua.gr

${ }^{5}$ Department of Earth Sciences, University of Perugia, 06100 Perugia, Italy

${ }^{6}$ Technological Educational Institution of Halkida, 34400 Psachna, Evia Island, Greece, gleontakianakos@yahoo.gr,vasta@teihal.gr

\begin{abstract}
For the purpose of the current study, we examined two paintings, an original and a fake one, entitled "Still life with grapes", and claimed both to be created from the Greek Painter G. Iakovidis. The current Research Project has been carried out at the Centre Nikias, an innovative Research Centre specialised on certification, maintenance and restoration of art works.

Raman spectroscopic analysis has been carried to verify the authenticity of the used pigments and also the originality of the two paintings. The Raman spectra acquired confirmed four different colours in both painting 's pigments: red, blue, white and yellow. For the first painting Cinnabar for the red pigment, Ultramarine for the blue pigment, White earths for the white pigment and Yellow ochre for the yellow pigment. In the second painting the colours used verified as synthetic pigments. We identified the presence of Cadmium red for the red colour, Cobalt blue for the blue pigment, Zinc white for the white and Cadmium yellow for the yellow one.
\end{abstract}

Key words: Raman spectroscopy, painting authenticity, archaeometry.

\section{Пері́ $\eta \psi \eta$}

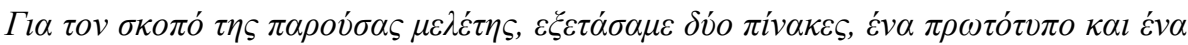

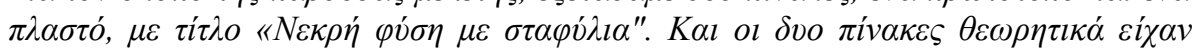

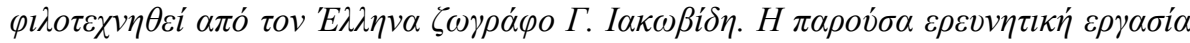

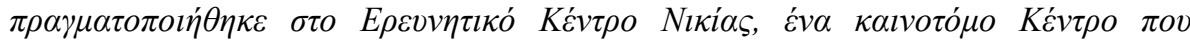

XLVII. No $1-392$ 


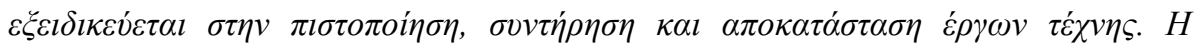

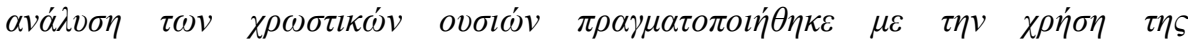

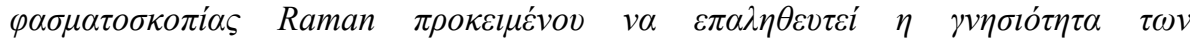

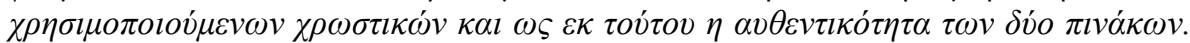

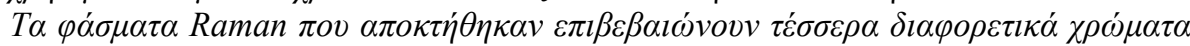

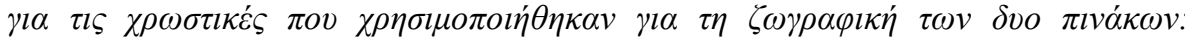

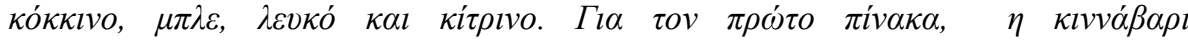

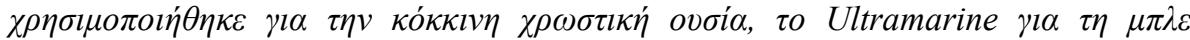

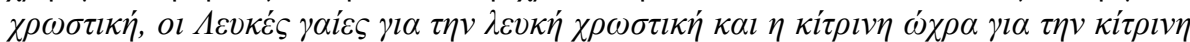

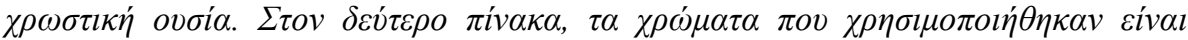

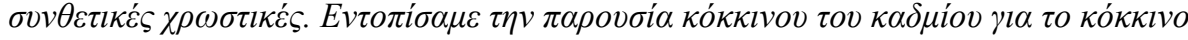

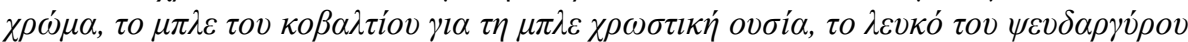

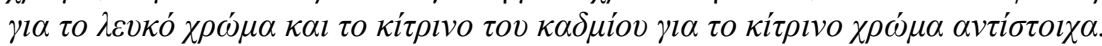

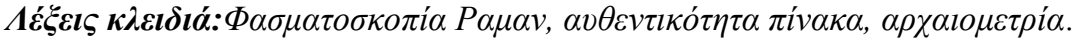

\title{
1. Introduction
}

Art works have, for many centuries, constituted a point of high interest, and even worship. The quality and the spirituality the works have expressed, their creator's fame and their purchase value offered an elevation to their owners' status. Nowadays their acquisition, other than the aforementioned aesthetic and cultural education, it constitutes an alternative form of investment globally.

While this market began to extend, the value of many works of art soared to extraordinary amounts. At the same time the systematic copy and sale of counterfeit work was developed and extended. This fact created the need for a certification of the art work's authenticity. The long and insisting investigation and experimentation in materials along with different methods have helped individuals obtain the ability to distinguish the fakes from the originals. However, the development of technology and the ease of access in information, provide creators of counterfeit work with an arsenal of techniques and methods of reproduction that make it almost impossible to distinguish the authentic works by traditional means and methodology.

Raman spectroscopy has become an important technique in Art studies and Art History since about 1996, Ravindran et al. (2011), due principally to its non-destructive capacities, small amount of sample required, "no sample treatment", and high spatial resolution.

Textbook explanations of Raman Spectroscopy for Geologists, Gemmologists and Archaeologists are provided in Smith and Carabatos-Nedelec (2001) and Nasdala et al. (2004), and reviews on MRM applications are available in Smith $(2002,2005,2006)$. Furthermore, various databases for art work, depicting minerals, media, pigments as well as synthetic pigments can be found in Bell et al. (1997), Burgio and Clark (2001), Bouchard (2001), Bouchard and Smith (2003).

Other commercially available databases are: S.T. Japan Europe GmbH (http://www.stjapaneurope.de) with 8.694 searchable Raman spectra of hydrocarbons, dyes, pigments, minerals and inorganics, Fiveash Data Management Inc. (http:// fdmspectra.com) with 6051 mineral spectra and 600 Raman spectra of organics, Thermo Fisher scientific Inc. (http://ramansearch.com) over 16000 Raman spectra and RASMIN Raman spectra database of minerals and inorganic materials.

An in situ analytical operation was carried out at the premises of Nikias Centre in two art works both to be claimed as G. Iakovidis's paintings. Extended, non-destructive analysis of the pigments was carried out in an attempt to identify the pigments and thus reveal the originality of the art works. One can simply edit the document you are now viewing. 


\section{Materials and Methods}

Two painting were studied by means of Raman spectroscopy. The paintings studied are depicted in Figure 1.They are both of same dimensions $50.5 \times 33 \mathrm{~cm}$, made of oil in canvas.

A Delta Nu Inspector Raman was used at Nikias Research Centre of Athens, Greece. The analyses were carried out using a near infrared $785 \mathrm{~nm}$ laser. A calibration of the instrument was obtained with a standard of Si yielding a characteristic peak at the $520.5 \mathrm{~cm}-1$. Preparation of the samples was not at all necessary and the paintings were simply placed in front of the focused $785 \mathrm{~nm}$ laser beam in their normal form. The video camera of the Raman system was employed in order to be able to observe magnified images on different areas of the paintings. The power of the laser was $120 \mathrm{~mW}$ at the source. The Raman spectra were acquired using accumulation time of $10 \mathrm{~s}$ for a frequency range 200-1800 cm-1. The Raman spectra were processed with the Nuspec software.

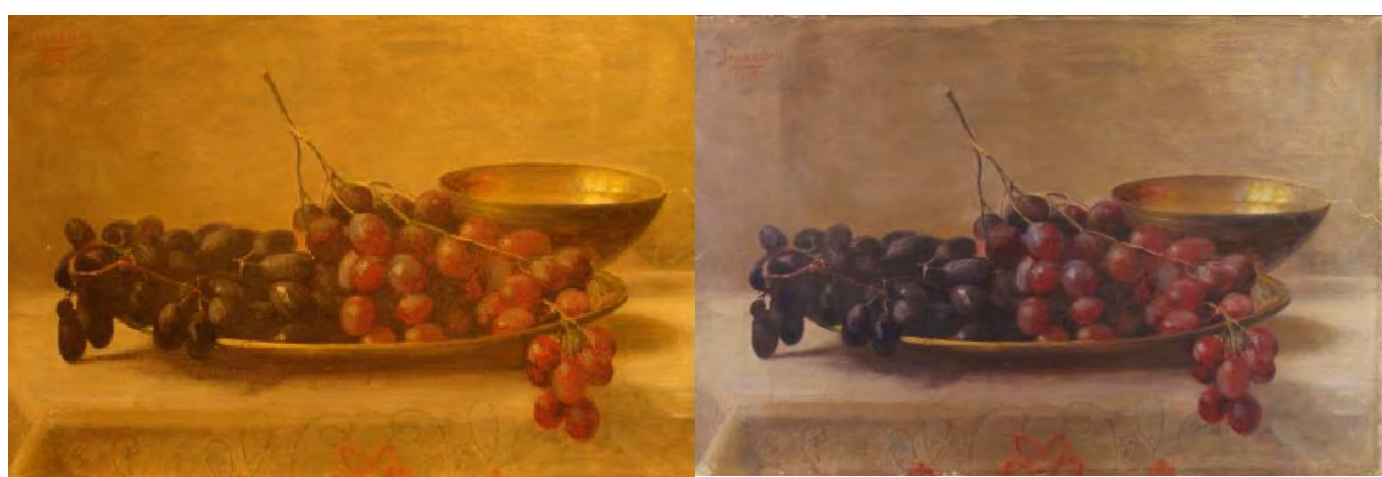

Figure 1 - Still life with grapes, oil in canvas. Both paintings claimed to be painted by $G$. Iakovidis.

\section{Results and Discussion}

The Raman spectra acquired during the analysis of the paintings, confirmed the authenticity of one of the paintings.

The examination has shown that different pigments were used in the two paintings. As regards the first painting the pigments detected were: Cinnabar for the red pigment used in red grapes, the signature of the artist, the patterns on the table cover and the inner part of the bowl. Cinnabar has its main characteristic Raman band at about $244 \mathrm{~cm}-1$ (Figure 2a). Ultramarine for the blue pigment used in blue grapes and the patterns on the table cloth. Ultramarine has its main characteristic Raman band at about $545 \mathrm{~cm}-1$ (Figure $2 \mathrm{~b}$ ). The white pigment used in light shading of the grapes, patterns, platter and bowl gave a Raman spectra with characteristic band at 385 and $1085 \mathrm{~cm}-1$ attributable to white earths (Figure 2c). Yellow ochre which have characteristic peak at $368 \mathrm{~cm}-1$ (Figure 2d) has been used for the background, table cloth, bowl and platter.

The identification of the prementioned mineral pigments indicates that this painting represents the authentic one.

In the second painting, denoted as "fake", the colours used verified as synthetic pigments. In particular, we identify the presence of Cadmium red (main Raman peaks at 1390, 1549 and 1592 $\mathrm{cm}-1$ ) for the red pigment used to paint the red grapes, the red patterns on the table cloth and the signature of the artist (Figure 3a). Cadmium yellow (Raman peaks at 222, 317, 1301 and $1446 \mathrm{~cm}$ 1) for the yellow pigments used for the platter, bowl, table cloth and background (Figure $3 \mathrm{~b}$ ). Zinc white (Raman peaks at 438, 1299 and $1443 \mathrm{~cm}-1$ ) for the white pigment used in lighting shades (Figure 3c) and Cobalt blue (Raman peaks at 1336 and $1524 \mathrm{~cm}-1$ ) for the blue pigment used for blue grapes and pattern on the table cloth (Figure 3d).

\section{No $1-394$}




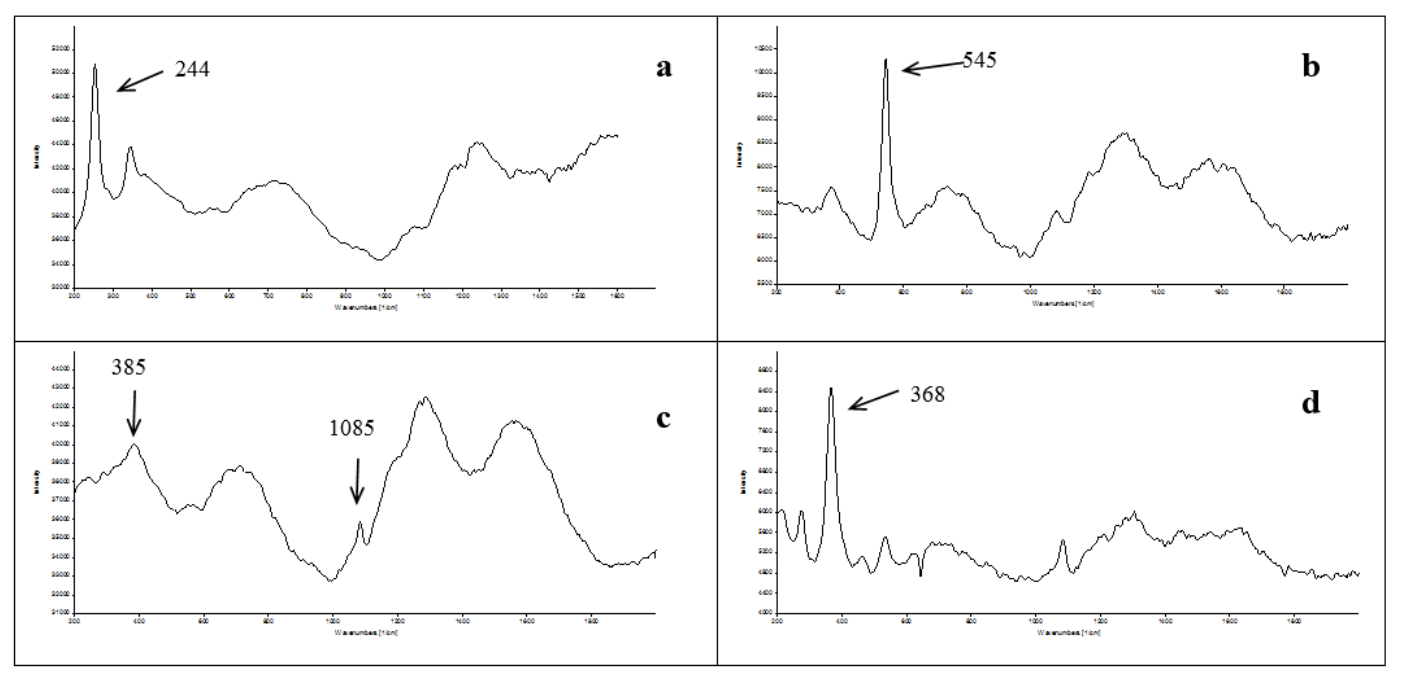

Figure 2 - Raman spectra of pigments used in the original Iakovidis's painting: a. Cinnabar, b. Ultramarine, c. White earths, d. Yellow ochre.

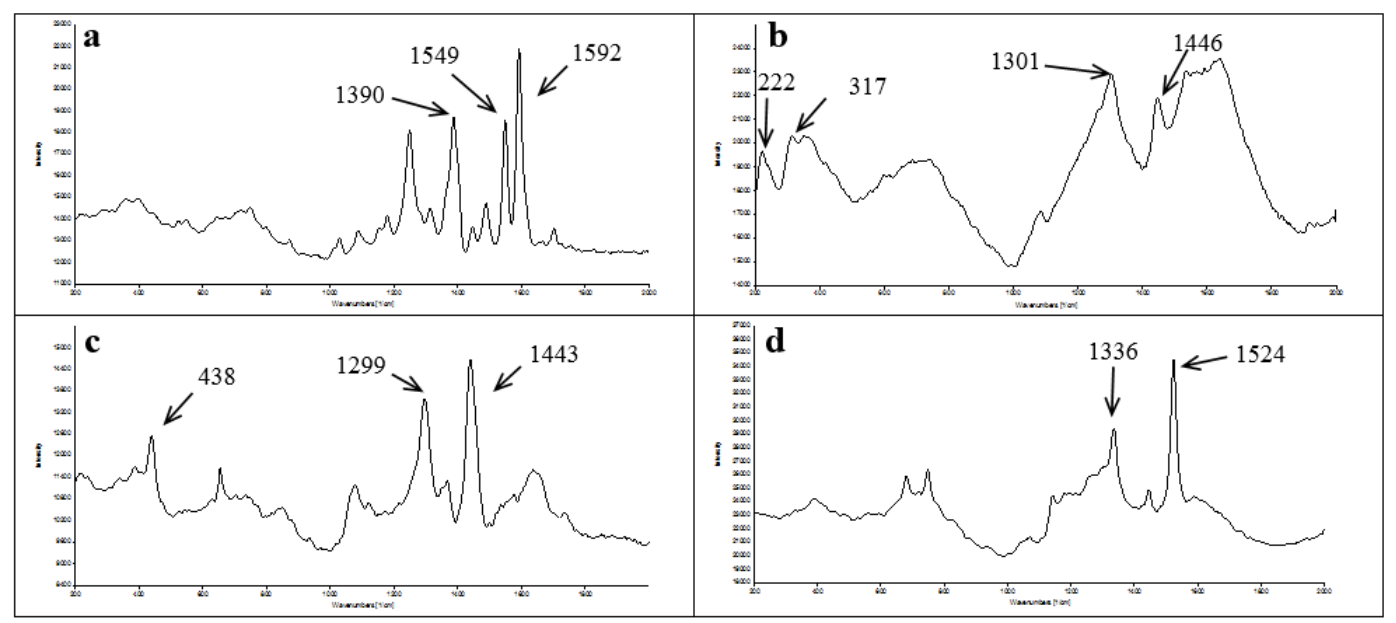

Figure 3 - Raman spectra used in the "fake" Iakovidis's painting: a. Cadmium red, b. Cadmium yellow, c. Zinc white, d. Cobalt blue.

The pigments used in the second painting were modern synthetic pigments which weren't in use during the active period of the mentioned painter (1853-1932 A.C.). A further comparison of the results with Centre Nikias's extended database demonstrates the release of the current synthetic pigments after Iakovidis death. During Iakovidis era, painters used mainly minerals as colorants due to their physical structure and reaction with binding agents (oil, gum Arabic, glue, gelatine etc.) which gave a superbly flexible and permanent paint film Willard et al. (1981), Arvin (1991).

\section{Conclusions}

The comparison of each spectrum with the extended database of Nikia's Centre revealed the presence of the pigments used in one of the paintings as following: Cinnabar for the red pigment, Ultramarine for the blue pigment, White earths for the white pigment and Yellow ochre for the yellow pigment. The identification of the mineral pigments indicates that this painting represents the authentic one. In the second painting, denoted as "fake", the colours used verified as synthetic 
pigments. In particular, we identify the presence of Cadmium red for the red, Cadmium yellow for the yellow, Zinc white for the white and Cobalt blue for the blue pigment.

\section{Acknowledgments}

The authors would like to acknowledge Mr J. Giouvanopoulos owner of the Research Centre Nikias for the data provided.

\section{References}

Arvin L. 1991. Scribes, Scripts and Books: The Book of Art from Antiquity to the Renaissance, Chicago, IL: American Library Association.

Bell M., Clark R.J.H. and Gibbs P.J. 1997. Raman spectroscopic library of natural and synthetic pigments (pre w1850 AD), Spectrochimica Acta, A 53, 2159-2179.

Bouchard M. 2001. Evaluation des Capacités de la Microscopie Raman dans la Caractérisation Minéralogique et physicochimique de Matériaux Archéologiques: Métaux, Vitraux \& Pigment, $\mathrm{PhD}$ dissertation, Museum national d'histoire naturelle, Spectrochimica Acta, Part A, $57,1491-1521$.

Bouchard M. and Smith D.C. 2003. Catalogue of 45 reference Raman spectra of minerals concerning research in art history or archaeology, especially on corroded metals and coloured glass, Spectrochimica Acta, Part A, 59, 227-266.

Burgio L. and Clark R.J.H. 2001. Library of FT-Raman spectra of pigments, minerals, pigment media and varnishes, and supplement to existing library of Raman spectra of pigments with visible excitation, Spectrochimica Acta, Part A, 57, 1491-1521.

Nasdala L., Smith D.C., Kaindl R., Gaft M. and Ziemann M.A. 2004. Raman spectroscopy: Analytical perspectives in mineralogical research, in: Spectroscopic Methods in Mineralogy (A. Beran \& E. Libowitzky, editors). EMU Notes in Mineralogy 6, Eotvos University Press, Budapest, 281-343.

Ravindran T.R., Arora A.K., Ramya S., Subba Rao R.V. and Baldev Raj J. 2011. Raman spectroscopic study of medieval Indian art of 17th Century, Raman Spectroscopy, 42, 803.

Smith D.C. and Carabatos-Nedelec C. 2001. Raman Spectroscopy Applied to Crystals: Phenomena and Principles, Concepts and Conventions, in: LEWIS, I. and EDWARDS, H.G.M. (Eds), A Handbook on Raman Spectroscopy, 9, 349-422, Marcel Dekker Inc.

Smith D.C. 2002. Archaeoraman and Mobile Raman Microscopy (MRM): from pigments in aerial wall-paintings to gemstones in submarine archaeometry, Congress Georaman, Acta Universitatis Carolinae, Geologica, Praha, 46/1, 84-86.

Smith D.C. 2005. Jewellery and precious stones, Raman Spectrometry in Archaeology and Art History, The Royal Society of Chemistry, 21, 335-378.

Smith D.C. 2006. A review of the non-destructive identification of diverse geomaterials in the Cultural Heritage using different configurations of Raman Spectroscopy, in: Maggetti, M., Messiga, B. (Eds). Invited paper, ch. 2, 9-32. Proceedings, 32nd International Geological Congress, Florence, August 2004, "Geomaterials in Cultural Heritage", Geol. Soc. London, Spec. Pub., 257.

Willard H.H., Meritt L.L., Dean J.A. and Settle F.A. 1981. Instrumental Methods of Analysis, 6th ed., Van Nostrand: New York, ch. 2. 